\title{
Watershed planning and development plan by using RS and GIS of Sangharinala watershed arang
}

P.K. Jamrey and V. K. Pandey

Received : 15.09.2017; Revised : 18.02.2018; Accepted : 27.02.2018

See end of the Paper for authors' affiliation

Correspondence to :

\section{P.K. Jamrey}

R.K.M. Agriculture Training and Demonstration Centre, Brehibeda, Narayanpur (C.G.) India

Email : pravinjamrey@ gmail.com
- ABSTRACT : The aim of the project is to develop an action plan for watershed management. Watershed management is the process of creating and implementing plans, programmes and projects to sustain and increase watershed functions that affect the plants, animal and human communities inside watershed boundary (Wikipedia). The recent technologies like remote sensing and GIS support use to giving a quicker and cost effective analysis of various applications with accuracy for planning. It also gives a better perspective for understanding the problems and, therefore, helps planners to evolve a better solution for sustainable development. From the final output of these themes generate pond, grassed waterways, percolation tank and check dams are recommended for the study area, mainly to control sedimentation from the catchments. To increase the groundwater recharge and vegetative cover to control soil erosion, various action plans like construction of recharge structures, afforestation etc. have been proposed. This project describes in brief the work carried out for the study area using remote sensing and GIS.

- KEY WORDS : : Watershed, Watershed development, ArcInfo, IRDAS imagine, DEM, Drainage map, Sangharinala

- HOW TO CITE THIS PAPER : Jamrey, P.K. and Pandey, V.K. (2018). Watershed planning and development plan by using Rs and GIS of Sangharinala watershed arang. Internat. J. Agric. Engg., 11(1) : 123-127, DOI: 10.15740/HAS/IJAE/11.1/123-127. 